УДК 539.4

DOI: 18.101/2306-2363-2019-2-3-3-6

\title{
РОЛЬ АМПЛИТУДЫ КОЛЕБАНИЙ ПРИ АКУСТИЧЕСКОМ РАЗДЕЛЕНИИ НАНОПОРОШКОВ
}

\author{
(C) С. В. Калашников \\ научный сотрудник \\ Институт физического материаловедения СО РАН \\ 670047, Улан-Удэ, ул. Сахьяновой, 6 \\ директор ЦКП, \\ Бурятский государственный университет \\ 670000, Улан-Удэ, ул. Смолина, 24а \\ E-mail: betch_kail@mail.ru
}

\author{
(C) А. В. Номоев \\ доктор физико-математических наук \\ заведующий лабораторией физики композитных материалов \\ Институт физического материаловедения СО РАН \\ 670047, Улан-Удэ, Сахьяновой, 6 \\ E-mail: nomoevav@mail.ru
}

Рассмотрены закономерности акустического разделения нанопорошков - перераспределения частиц в узлы и пучности волны на поверхности поперечно колеблющейся пластины. Выявлена зависимость характерного размера разделения частиц от амплитуды колебаний. Закономерности открывают возможности применения акустического разделения ультрадисперсных материалов в газовой среде без жидкости. Разделения при низких частотах позволяет использовать колебательные поверхности больших размеров, изменение частоты и амплитуды колебаний способствует регулированию размера частиц в разделенных фракциях. Что позволяет получать нанопорошки с заданными размерами частиц и увеличивать эффективность их применения в материаловедении и других областях.

Ключевые слова: нанопорошок; наночастица; распределение по размерам; фигуры Хладни; фракционирование; сепарация; амплитуда колебаний.

\section{Для цитирования}

Калашников С. В., Номоев А. В. Роль амплитуды колебаний при акустическом разделении нанопорошков // Вестник Бурятского государственного университета. Химия. Физика. 2019. Вып. 2-3. С. 3-6.

Акустический метод разделения нанопорошков $[1,2]$ основан на фигурах Хладни, построенных порошком на поперечно колеблющейся пластине, где частицы пространственно разделяются в пучности или узлы стоячих волн в зависимости от своего размера. Первые упоминания об использовании микрофигур Хладни для разделения наноразмерных материалов содержатся в [3], где авторы пришли к выводу, что за движение частиц к пучности отвечает приповерхностное вихревое течение Шлихтинга [4], имеющее высоту своего центра от пластины, равную глубине проникновения вязких акустических волн $\delta=\sqrt{ } 2 v / \omega$. На частицы, размер которых меньше $\delta$, действует только поток вблизи поверхности колеблющейся пластины и внаправлении узла; для частиц с размером больше 
$2,8 \delta$ - потоки вихря Шлихтинга в целом и поток нижней части вихря Рэлея, которые приводят частицу к пучности. Следовательно, для разделения частиц с размером 100 нм в воздухе необходима очень высокая частота механических колебаний - 1 ГГц, что ограничивает практическую ценность метода во многих приложениях.

В рамках работы, в результате серии экспериментов, была выявлена закономерность между амплитудой колебаний пластины и средними размерами частиц порошка диоксида кремния, отобранного из узловых линий и из пучности колебаний (рис.). Средние размеры наночастиц, отобранных из пучности, значительно меньше размера частиц из узловой линии, при этом с увеличением амплитуды растет и средний диаметр частиц обеих фракций. Средний размер частиц, отобранных из узловых линий, при значениях амплитуды от 100 мкм и выше не изменяется, что может быть объяснено максимальным значением размера конгломератов порошка диоксида кремния в воздухе для данного эксперимента $(3,5-5$ мкм). Наибольшая возможная амплитуда колебаний составляла 600 мкм, при большем значении фигуры Хладни размывались из-за большой кинетической энергии, передаваемой частицам от пластины. При амплитуде колебаний пластины, меньшей 1 мкм, фигуры не образовывались ввиду малой кинетической энергии пластины, и как следствие - малой скорости потоков среды.

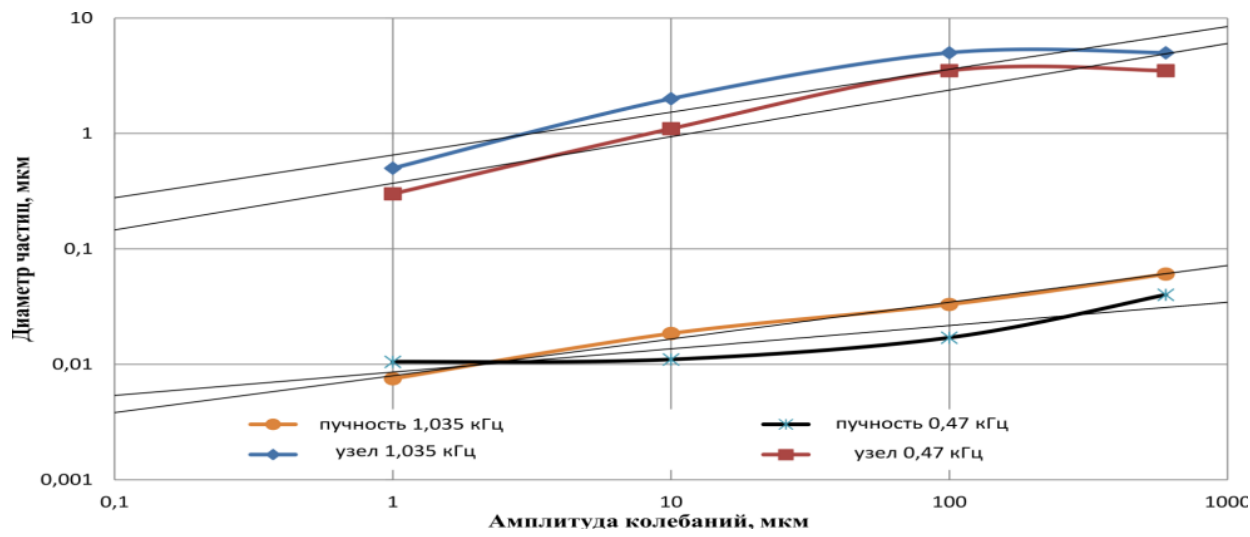

Рис. Зависимость среднего диаметра частиц диоксида кремния, отобранных из узловых линий и из пучностей колеблющегося в воздухе кантилевера с частотой 0,47 и 1,035 кГц

Таким образом, экспериментальные данные разделения нанопорошка на поперечно колеблющейся поверхности показывают, что разделение возможно при сравнительно низких частотах $(0,5-1$ кГц), когда размер разделяемых частиц много меньше толщины слоя $\delta$ приповерхностного течения. Выявлено наличие зависимости размера частиц во фракциях из пучности и узлов колебаний не только от частоты колебаний, но и от амплитуды. Последняя особенно важна при низкой частоте, так как размер разделенных частиц при этом может регулироваться изменением амплитуды, что важно с точки зрения применения акустического метода разделения в прикладных целях. 
Выявленные закономерности открывают возможности применения акустического разделения ультрадисперсных материалов, имеющего такое преимущество, как способность разделения в газовой среде без жидкости. Возможность разделения при низких частотах позволяет использовать колебательные поверхности больших размеров, изменение частоты и амплитуды колебаний способствует регулированию размера частиц в разделенных фракциях. Это открывает новые возможности получения нанопорошков с заданными размерами частиц, что, в свою очередь, увеличит эффективность их применения в материаловедении и других областях.

Материалы публикаиии подготовлены с использованием оборудования ЦКП «Научные приборы» ФГБОУ ВО «Бурятский государственный университет имени Доржи Банзарова».

Работа выполнена в рамках проектов по государственному заданию Института физического материаловедения СО РАН и РФФИ № 18-42-030004 — p_a.

\section{Литература}

1. Калашников С. В., Номоев А. В., Дзидзигури Э. Л. Использование метода инверсных фигур Хладни для разделения частиц по размерам // Физика и химия обработки материалов. - 2014. - № 4. - С. 68-73.

2. Калашников С. В, Лыгденов В. Ц., Номоев А. В. и др. Разделение наночастиц диоксида кремния по размерам методом фигур Хладни // Актуальные проблемы гуманитарных и естественных наук. - 2012. — № 8 (43). - С. 21-28.

3. Dorrestijn M., Bietsch A., Açikalin T. and etc. Chladni Figures Revisited Based on Nanomechanics // Phys. Rev. Lett. — 2007. — № 98. — P. 026102 (1-4).

4. Schlichting H. Boundary layer theory. — New-York: McGraw-Hill, 1955. - 535 p.

\section{THE ROLE OF VIBRATION AMPLITUDE IN ACOUSTIC SEPARATION OF NANOPOWDERS}

\section{S. V. Kalashnikov}

Research

Institute of Physical Materials Science SB RAS

670047, Ulan-Ude, Sakhyanova, 6,

Director of Core Facilities

Buryat State University

670000, Ulan-Ude, Smolina, 24A

E-mail: betch_kail@mail.ru

\section{A. V. Nomoev}

Doctor of Physical and Mathematical Sciences

Head of the laboratory of Physics of Composite Materials

Institute of Physical Materials Science SB RAS

670047, Ulan-Ude, Sakhyanova 6

E-mail: nomoevav@mail.ru

The regularities of the acoustic methods of nanopowders separation - redistribution of particles into nodes and wave antinodes on the surface of a transversely oscillating plate are 
considered. The dependence of the characteristic size of particle separation on the amplitude of oscillations is revealed. The regularities open the possibility of applying acoustic separation of ultrafine materials in a gas environment without a liquid. Separation at low frequencies allows the use of large vibrational surfaces, changing the frequency and amplitude of oscillations helps to regulate the particle size in the separated fractions. This makes it possible to obtain nanopowders with specified particle sizes and increase the efficiency of their application in materials science and other fields.

Keywords: nanopowder, nanoparticle, size distribution, Chladney figures, fractionation, separation, oscillation amplitude 